\section{Changes in Lysozyme during Egg White Thinning}

\author{
Akio Kato, Tazuru Wakinaga, \\ Naotoshi MATSUDOMI and \\ Kunihiko KoBAYASHI \\ Department of Agricultural Chemistry, Faculty \\ of Agriculture, Yamaguchi University, \\ Yamaguchi, Japan
}

Received June 13, 1977

Many workers ${ }^{1 \sim 4)}$ have proposed that ovomucinlysozyme interaction is responsible for the rigidity of the gel structure in thick white and the interaction decreased during the thinning. However, there has been little information as to whether ovomucin-lysozyme interaction actually exists in the egg white. In addition, little is hitherto known about the behavior of lysozyme in the egg white during the thinning.

This paper describes the changes in lysozyme during egg white thinning and the possible effect of lysozyme on egg white thinning.

Thick white, upon centrifugation at $87,000 \times g$ for $1 \mathrm{hr}$, separated into two fractions, a clear supernatant and a firm pellet, or liquid and gel fractions. Disc electrophoresis in the presence of $0.1 \%$ SDS was performed on $7 \%$ polyacrylamide gel in $0.1 \mathrm{~m}$ sodium phosphate buffer, $\mathrm{pH} 7.2$, at $8 \mathrm{~mA}$ per column at room temperature for $3 \mathrm{hr}$. The gels were stained for protein with $0.05 \%$ coomassie blue solution in $10 \%$ acetic acid containing $25 \%$ isopropyl alcohol. The concentration of proteins on electrophoretic patterns was determined by measuring their color densities at $565 \mathrm{~nm}$ on a densitometer (Densitrol DMU-33C, Toyo Kagaku, Japan). The activity of lysozyme was measured by the method of Imoto and Yagishita. ${ }^{b)}$

The SDS gel electrophoretic patterns of the gel and liquid fraction in the thick white are shown in Fig. 1. The fastest moving band was identified as lysozyme in the SDS gel electrophoretic patterns of egg white. Calculated from the electrophoretic patterns in Fig. 1, the relative concentration of lysozyme of the gel fraction was 1.4 times that of the liquid fraction in the fresh thick white. After storage for 5 days, there were little differences in lysozyme contents between the gel and liquid fraction in the thick white, as shown in Fig. 1. This was also confirmed from the changes in lysozyme

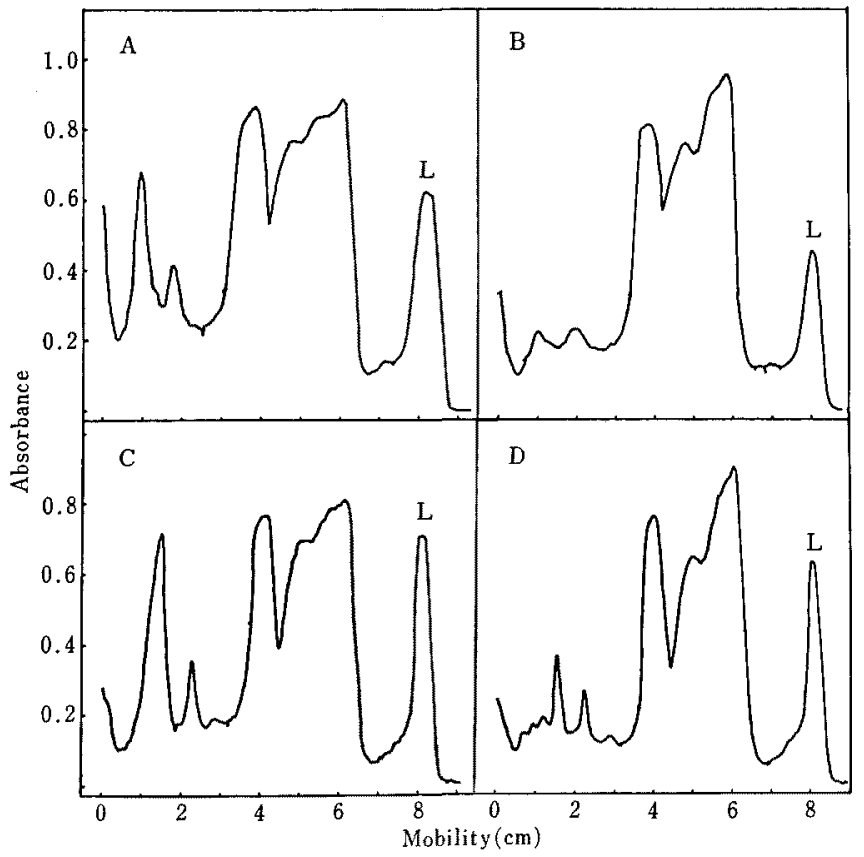

Frg. 1. SDS Gel Electrophoretic Patterns of the Gel and Liquid Fraction in the Fresh and Stored Thick White.

(A) gel fraction in the fresh thick white, (B) liquid fraction in the fresh thick white, (C) gel fraction in the stored thick white, (D) liquid fraction in the stored thick white. Peak $\mathrm{L}$ represents lysozyme. Thick white employed in (C) and (D) was obtained from the thick white which remained after storing at $30^{\circ} \mathrm{C}$ for 5 days. 


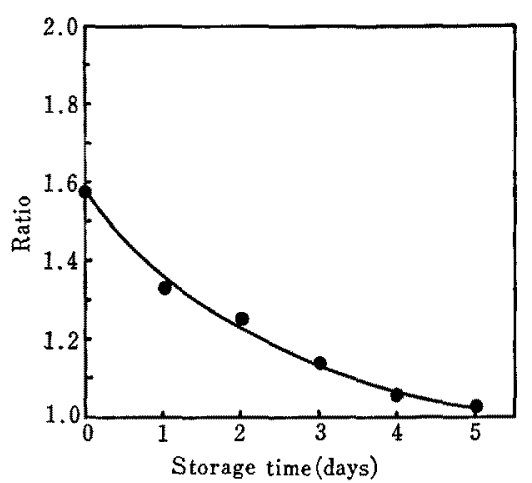

Fig. 2. Changes in the Ratios of Lysozyme Content of Gel Fraction to That of Liquid Fraction during Storage of Thick White.

Lysozyme contents were estimated from the specific activity of lysozyme in each fraction.

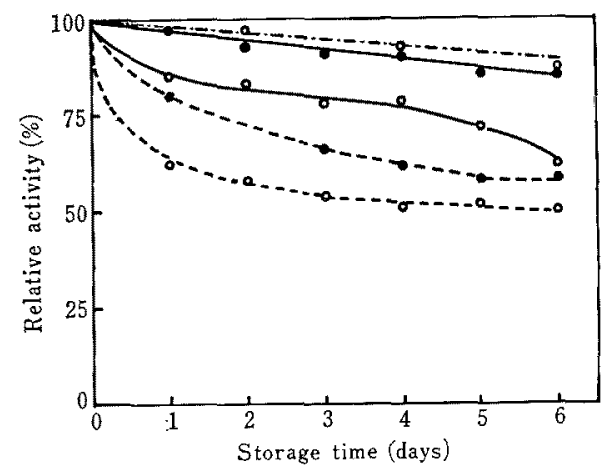

FIG. 3. Effect of Storing Temperature or $\mathrm{pH}$ on Relative Activity of Lysozyme in Thick White.

- $-5^{\circ} \mathrm{C}$ (final pH 9.0), $0-020^{\circ} \mathrm{C}$ (final pH 9.3), --- $30^{\circ} \mathrm{C}$ (final pH 9.4), $\mathrm{O}-\mathrm{O} 40^{\circ} \mathrm{C}$ (final pH 9.5), $0-\cdots$ Thick white was stored in an atomosphere of carbon dioxide at $30^{\circ} \mathrm{C}$ (final $\mathrm{pH} 6.5$ ).

content, estimated from the activity, of the gel and liquid fraction in the thick white during storage, as shown in Fig. 2. It is suggested from these results that the lysozyme has a strong affinity to the gel in the fresh thick white, but dissociates from the gel into the liquid fraction in the thick white during an earlier phase of storage. The dissociation of lysozyme from the gel may be caused by the dissociation of F-component of ovo- mucin in the gel fraction during storage, as shown in the previous reports, ${ }^{\beta \sim 8)}$ but may also be caused by the changes in lysozyme itself during storage.

The lysozyme activity in the thick white correspondingly decreased, at a rate depending on the temperature at which the thick white was kept, as shown in Fig. 3. The lower the storing temperature, the smaller the decrease of lysozyme activity. The lysozyme activity of the thick white was also affected by the $\mathrm{pH}$ of the white, as shown in Fig. 3. The $\mathrm{pH}$ of thick white was lowered in an atmosphere of carbon dioxide. The lysozyme activity of the thick white stored in pH 6.5 was little lowered. It was suggested in the previous report $^{8}$ that any appreciable egg white thinning might hardly occur when the eggs were stored in an atmosphere of carbon dioxide at $30^{\circ} \mathrm{C}$. It is interesting that the lysozyme activity of the thick white was remarkably affected by the storing temperature and $\mathrm{pH}$, corresponding to the main causal factors of the egg white thinning. This suggests that the denaturation of lysozyme in the thick white during storage may be at least partly responsible for the egg white thinning. The gel structure in the fresh thick white is probably supported in a regularly ordered manner in which ovomucin fiber are surrounded by such proteins as lysozymes having a strong affinity to ovomucin. Therefore, the weakening of the gel structure of thick white during egg white thinning may be caused not only by the changes in ovomucin but also by the denaturation of such proteins as lysozyme supporting the gel structure of thick white.

\section{REFERENCES}

1) O. J. Cotterill and A. R. Winter, Poultry Sci., 34, 679 (1955).

2) J. Brooks and H. P. Hale, Biochim. Biophys. Acta, 32, 237 (1959).

3) J. Brooks and H. P. Hale, ibid., 46, 289 (1961).

4) D.S. Robinson and J. B. Monsey, J. Sci. Food Agric., 23, 893 (1972).

5) T. Imoto and K. Yagishita, Agric. Biol. Chem., 35, 1154 (1971).

6) A. Kato, R. Nakamura and Y. Sato, ibid., 34, 1009 (1970).

7) A. Kato, R. Nakamura and Y. Sato, ibid., 35, 351 (1971).

8) A. Kato and $Y$. Sato, ibid., 36, 831 (1972).

9) A. Kato, R. Nakamura and Y. Sato, ibid., 36, 947 (1972) 